\title{
2 The neglected importance of floral traits in trait-based plant community assembly
}

3 Anna E-Vojtkó ${ }^{1,2 *}$, Francesco de Bello ${ }^{1,3}$, Walter Durka ${ }^{4,6}$, Ingolf Kühn ${ }^{4,5,6}$ and Lars

4 Götzenberger ${ }^{1,2}$

$6{ }^{1}$ Department of Botany, Faculty of Science, University of South Bohemia, České Budějovice,

$7 \quad$ Czech Republic

$8 \quad 2$ Institute of Botany, Czech Academy of Sciences, Třeboň, Czech Republic

$9 \quad{ }^{3}$ CIDE-CSIC, Montcada, Valencia, Spain

$10{ }^{4}$ Helmholtz Centre for Environmental Research -UFZ, Department of Community Ecology,

11 Halle, Germany

$12{ }^{5}$ Institute of Biology/Geobotany and Botanical Garden, Martin Luther University Halle-

13 Wittenberg, Halle, Germany

$14{ }^{6}$ German Centre for Integrative Biodiversity Research (iDiv) Halle-Jena-Leipzig, Leipzig,

15 Germany

17 Running title: Floral traits in plant community assembly

$18 *$ *orrespondence: annavojt@gmail.com 


\section{Abstract}

Aims: Floral traits are frequently studied in population biology and evolutionary ecology but are rarely considered in functional trait-based studies focusing on the assembly of communities. We address this gap in trait-based community assembly by synthesizing the existing literature on processes driving floral and pollination-related trait patterns at community scales. We highlight limitations of the field due to lack of data and suggest potential directions of future research.

Methods: We conducted a systematic literature search collating studies that investigated floral traits in the context of plant community assembly, which allowed us to synthesise the current state of the art and point out important gaps in knowledge.

Conclusions: The literature review shows that including pollination related traits in community assembly studies can shed new light on species coexistence patterns not accounted by other types of traits. The synthesis presented here shows the diversity of approaches and existing techniques which can generate a step forward in this open field of research. What currently seems to hinder comprehensive analyses of floral traits at community levels is the lack of data, particularly in existing large repositories for traits worldwide, as well as a gap in linking modern co-existence theory with floral traits.

Keywords: community assembly, competition, facilitation, functional diversity, plant-pollinator interactions, reproductive success, trophic interactions 


\section{Introduction}

Understanding the rules of community assembly and species coexistence is one of the oldest and most fundamental aims of ecological research (Götzenberger et al., 2012). To date, numerous potential ecological processes have been identified as drivers of species sorting into communities. Among these, abiotic conditions and biotic interactions, as well as dispersal, are generally agreed to have an important role, beside stochastic events (Cornwell, \& Ackerly, 2009). Abiotic and biotic processes act as a series of filters, selecting species from a regional species pool into local communities (Zobel, 2016) based on their functional characteristics which make them suitable for the particular habitat (Díaz, Cabido, \& Casanoves, 1998). Such characteristics, i.e. "functional traits", are defined as "any morphological, physiological or phenological feature measurable at the individual level, which impacts fitness indirectly via its effects on growth, reproduction and survival" (Violle et al., 2007). Although, by definition, reproduction is one of the three main pillars of fitness, some reproductive traits, and especially floral traits have only played a minor role in functional trait ecology in general, and in trait based community assembly studies in particular.

Traits frequently used in functional ecology are principally those related to the leaf-heightseed (LHS) strategy scheme (Westoby, 1998). These traits are connected to growth and survival, i.e. canopy height determining competitive ability, seed mass affecting dispersal and establishment ability, and specific leaf area defining resource investment. Although these traits are easy to measure and are good proxies for crucial biological functions, they fail to provide information about some of the most important organs and structures involved in sexual reproduction. Floral traits, in this sense, provide a very useful and complementary tool for understanding various reproductive processes (e.g. Karron et al., 2012). Unfortunately, they are generally neglected in 
functional ecology research which is also reflected by their absence from the most recent handbook of standardized protocols of plant traits (Pérez-Harguindeguy et al., 2013). However we can expect that floral traits may vary in response to both biotic and abiotic drivers (as "response traits"), and affect ecosystem functioning (as "effect traits", Lavorel, \& Garnier, 2002) through providing a connection to other trophic levels (Lavorel et al., 2013).

We use the term "floral traits" to refer to characteristics of the flower having a biological function, and an ecological importance by affecting the fitness of the individual. We do not use the term "reproductive traits" to avoid confusion, since this generally includes seed and fruit characteristics, which we do not consider here. As flowers provide the setting for seed and fruit development that, when mature, replace the floral structures, there is also a temporal distinction between the two groups of traits in their general effect on plant fitness. These criteria help to distinguish floral traits (neglected in trait-based plant community studies) from traits that are frequently employed and for which data are widely available, e.g. seed size. Floral traits, in this sense, include traits involved in (i) sexual reproduction ability (as opposed to vegetative reproduction), (ii) cross-pollination vs. self-fertilization potential, and (iii) the physiology, morphology and phenology of flowers or inflorescences and the way they get pollinated (Klotz, Kühn, \& Durka, 2002). Although the connection between fitness and floral traits might seem weak in the case of certain species or habitats, in general, during the sexual reproduction phase in the plant's life cycle, floral traits, such as flower morphology and flowering time, become crucial for maximizing reproductive output (Larson and Funk 2016). In fact, flowering time can have a huge impact on the fitness of several type of species irrespective of their pollination type, as it has been shown that flowering during a time of high resource availability can have a critical benefit for viable seed production (Craine et al 2012). It is important to mention that not all species rely, 
always, on sexual reproduction and the importance of vegetative propagation could be predominant for certain species and in certain habitat types (Klimešová, Danihelka, Chrtek, de Bello, \& Herben, 2017). However, we hypothesize that a careful selection of floral traits will be relevant for the assembly of plant communities within several vegetation types.

The main goal of this synthesis is to link evidence from studies on community-scale pollination to current species coexistence and community assembly theory to better understand mechanisms driving floral trait patterns in diverse communities. We aim to review and synthesize the general trends in floral trait patterns and related processes, in order to support and direct future developments in this filed. We carried out a systematic literature search to assess existing evidence on community assembly patterns of floral traits. We specifically incorporate studies that are explicitly focusing on the community scale in a wide sense, thus including both biogeographical and local scale findings, but that do not focus on only a limited component of the whole community (i.e. species of a particular family, tribe, or genus occurring within a community). We also aim at demonstrating that floral traits are important determinants of community assembly, and that they are a vital component of the ecological strategy of plants that has so far been mostly neglected in studying the assembly of diverse plant communities.

In the review, we first summarize the different types of methodological approaches that are generally used to assess plant and pollinator communities and their interactions. In this synthesis, we then turn our attention to the particular approaches that use floral traits at the plant community level to describe assembly patterns. Based on a literature review, we synthesize reported patterns and related processes, and discuss the relevance of scale, as we incorporate studies on both biogeographical and local scales. In the succeeding section, we point out the lack of available floral trait data in most current databases as an important hindrance in advancing their involvement in 
community assembly studies. Finally, we provide a concise list of future steps to overcome data limitations and suggestions for research.

\section{Approaches used in community level pollination ecology}

The field of pollination ecology has a vast array of publications focusing on evolutionary processes, population dynamics and pollination mechanisms of single species or genera. However, few studies have dealt with pollination ecology on the community scale, where the main focus is shifted towards species co-existence patterns and assembly rules of interacting communities of plants and pollinators. It is important to note here that the field of pollination ecology has rarely applied the concept of community ecology on which much of vegetation ecology relies on. In pollination ecology a clade of co-occurring taxa are often considered a community. Though in vegetation ecology, and particularly in community assembly studies, communities consist of all or the majority of species co-occurring in a specific site, regardless of phylogenetic relationships or other criteria. In some cases, pollination studies on a well-defined component of the whole plant community (e.g. only animal pollinated species in network analysis) might also represent a meaningful community-level analyses. In the following sections, we briefly introduce the most common approaches of pollination ecology studies which consider communities (i.e. assemblages of co-existing species in a specified location) as the ecological unit of their research (Figure 1., Table 1).

In recent years the number of pollination network studies increased dramatically (Figure 1., Table 1. “A”; e.g., Junker et al., 2013; Junker, Blüthgen, \& Keller, 2015; Bennett et al., 2018a). The interaction networks between communities of plants and pollinators (reviewed by Vázquez, 
Blüthgen, Cagnolo, \& Chacoff, 2009 and Knight at al., 2018) offer a perfect study system for understanding mutualistic relationships between trophic levels (Blüthgen, Menzel, Hovestadt, Fiala, \& Blüthgen, 2007), and therefore, are strongly constrained by both animal and plant traits (e.g. Junker et al., 2013; Chamberlain et al., 2014; Maglianesi, Blüthgen, Böhning-Gaese, \& Schleuning, 2014; Schleuning, Fründ, \& García, 2015). Interaction networks combined with functional traits (Figure 1., Table 1. “AB”) can provide a deeper understanding of plant-pollinator trait matching (Sazatornil et al., 2016) and the validity of using pollination syndromes, i.e. whether a certain set of plant traits predetermine the group of potential pollinators (Lázaro, Hegland, \& Totland, 2008; Ollerton et al., 2009; Rosas-Guerrero et al., 2014). Evolutionary relationships might also have the potential to explain the structure of pollination networks. On the one hand, pollinators are known to show "clade-specialization", a preference on more closely related plant species (Vamosi, Moray, Garcha, Chamberlain, \& Mooers, 2014), which can be seen as sign of niche conservatism, i.e. closely related species share similar (pollination) niches due to shared evolutionary history (Losos, 2008). On the other hand, in certain plant-pollinator networks, phylogeny might be a weak predictor (Chamberlain et al., 2014).

In this rapidly developing field, new analytical tools have been proposed for approaches combining traits, phylogeny and networks (Ibanez, 2012; Ibanez, Lavorel, Puijalon, \& Moretti, 2013; Rafferty \& Ives, 2013; Bastazini et al., 2017; Laigle et al., 2018; Kantsa et al., 2018). Furthermore, methods for comparing networks along environmental and resource gradients (Tinoco, Graham, Aguilar, \& Schleuning, 2017; Pellissier et al., 2018), as well as ones explaining non-random community assembly patterns based on network structure (Kemp, Bergh, Soares, \& Ellis, 2019) are advancing fast and have a strong potential to contribute to fully addressing the role of traits shaping species interactions and community structures (Figure 1., Table 1. "ABC"). 

taxonomy; thus the assumption of a connection between certain morphological patterns (i.e. number of petals, stamens etc.) and phylogeny is implicit in this study subject. However, such expected niche conservatism of floral traits along phylogenetic trees has been met with very few attempts to explore whether floral traits indeed adhere to conservatism, e.g. through estimating the phylogenetic signal of these traits. Moreover, trait conservatism has been addressed at the community scale, where the phylogeny of the co-occurring species is considered. Although these approaches could help to reveal evolutionary processes driving functional trait-based community assembly (Figure 1., Table 1. "B"), results on this topic are scarce and have hitherto been contradictory. For instance, flower colour had a strong phylogenetic signal among species of a temperate grassland (Binkenstein, Renoult, \& Schaefer, 2013), but only a weak signal was found among species growing along an altitudinal gradient in the Himalayas (Shrestha, Dyer, Bhattarai, \& Burd, 2014). Junker, et al. (2015) reported a phylogenetic signal for three out of eight different quantitative floral traits, which is the most comprehensive study on the phylogenetic and functional assembly based on floral traits at the community scale to this date. There is some evidence on phylogenetic clustering of floral traits in both small sets of closely related species (trait evolution within phylogenetic clades) and small local communities representing a phylogenetically “dispersed" set of species. However, explicit assessments of larger species pools covering a larger part of the phylogenetic tree and thus including "deeper" nodes (early diversification) are still scarce and conducted only for few vegetative traits (Pennell et al., 2015).

The above-mentioned approaches focus on plant-pollinator interactions through analysing patterns in functional traits and phylogenetic relationships between species. However, to date, there are very few published studies to review in a comprehensive way. The above questions and 
themes are worth exploring further in the future, to shed new light on the ecology of plantpollinator interactions. Moreover, we must remark that these approaches completely ignore the abiotically pollinated plant species co-existing within the community (Figure 1). Species with different pollination modes might not be relevant in terms of pollination networks, but still have an effect on the abundance and/or fitness of neighbouring plants through competition for abiotic resources (Flacher, Raynaud, Hansart, Motard, \& Dajoz, 2015) or through heterospecific pollen transfer (Ashman, \& Arceo-Gomez, 2013).

\section{Floral traits in community ecology}

From the plants' perspective the available pool of pollinators can be considered a limiting "resource". Similar to other abiotic resources, pollinator scarcity might have a negative impact on the fitness of the plant, and the pollinators' capacity can be depleted. However, unlike abiotic resources, an increase in plant population size can increase pollinator availability by attracting more pollinators or providing better habitat and thus enhancing the amount and diversity of interactions. It might result, though, also in an increased competition for pollinators. Due to the ambiguity of this feedback, in natural communities both competition and facilitation for pollinators can occur between coexisting plant species (Feldman, Morris, \& Wilson, 2004; Pauw, 2013; Benadi, \& Pauw, 2018; Pauw, 2018). The presence or absence of given pollinators will thus potentially exert a biotic filtering effect favouring certain types of plants and limiting others within local communities (Wolowski, Carvalheiro, \& Freitas 2017). Although studying plant community assembly through floral traits without pollinator observations might not serve as an actual "shortcut" in understanding plant-pollinator patterns, as suggested by Pellissier, Alvarez, \& Guisan (2012), it could help us disentangle how plant communities are structured indirectly by this "biotic 
resource" (Fantinato, Del Vecchio, Giovanetti, Acosta, \& Buffa, 2017). Despite this potential, analysing floral traits does not have a long history in the field of community ecology. There have been, however, a growing number of studies published in recent years focusing on floral trait distribution patterns (Kantsa et al., 2017) in response to different abiotic (e.g. altitude, Junker, \& Larue-Kontic, 2018) and biotic drivers (Warring, Cardoso, Marques, \& Varassin, 2016) on different spatial scales (review on the scale dependency of facilitative processes: Braun, \& Lortie, 2019).

\subsection{Literature search}

We carried out a systematic literature search of studies on plant community assembly and floral traits in Web of Science. Our search terms were (plant* AND (pollinat* OR flower* OR floral*) AND trait* AND communit*) yielding 982 results (last accessed: 22. 02. 2018). While we scanned visually all titles from this list, we focussed more closely on the first 300 papers (ordered by relevance according to Web of Science) which were scanned also by abstract. Among the selected studies we skimmed all references and the context in which they were cited resulting in other potentially relevant articles. We excluded studies on i) populations/“communities" consisting of a limited selection of species (e.g. genera or small clades), ii) evolutionary processes without describing spatial patterns and iii) review, viewpoint/commentary or forum papers, book chapters and theoretical frameworks. The described criteria resulted in 21 studies which were clearly related to empirical studies on community assembly in the broad sense (for a brief summary on the aims of study, floral traits used and most important findings of each paper, see Appendix S1). In the next sections we describe and discuss the papers found in the context of current community assembly theory, in terms of processes shaping species co-existence and functional trait patterns on different spatial scales. 
The main processes driving non-random community assembly through plant-pollinator interactions are filtering, competition and facilitation (Sargent, \& Ackerly, 2008), which can create non-random patterns in floral traits among the co-occurring species of a community (Figure 1., Table 1. "BC"). In the traditional sense, filtering is mainly thought to be caused by environmental (i.e. abiotic) conditions directly. However, due to the connection that floral traits enable between trophic levels, abiotic conditions might also affect plants indirectly through the available pool of pollinators. Plant adaptations to maximize reproductive output by e.g. producing easily accessible flowers (Pellissier, Pottier, Vittoz, Dubuis, \& Guisan, 2010), increasing biomass allocation to floral structures (Fabbro, \& Körner, 2004) or promoting earlier and prolonged flowering (Makrodimos, Blionis, Krigas, \& Vokou, 2008) were found to be correlated with environmental gradients. However, correlation does not necessarily mean causation, as environmental filtering is equally likely to act on potential pollinators or directly on the plants themselves.

Plant species can also experience reduced reproductive output (pollen limitation) due to pollinator scarcity or environmental perturbations directly (reviewed by Bennett et al., 2018a). Loss in reproductive success can occur in certain environmental conditions, when plants fail to attract their potential pollinators because of e.g., poor light availability or other unsuitable abiotic conditions (Sargent, \& Ackerly, 2008). Therefore, small scale habitat filtering needs to be studied in the context of plant-pollinator interactions (e.g. Burkle, \& Irwin, 2010; Lázaro, Lundgren, \& Totland, 2015), thus combining the effects of abiotic and biotic conditions as well as temporal changes in plant communities (de Deus, \& Oliviera, 2016; Warring et al., 2016).

Similarly, disentangling the effect of biotic interactions - competition and facilitation - on the observed community patterns is not straightforward (e.g. Hegland, \& Totland, 2012). In theory, 
pollinator-sharing leads to competition that can be disadvantageous to at least one of the species involved (reviewed by Mitchell, Flanagan, Brown, Waser, \& Karron, 2009). On the one hand, competition for pollinators can cause reduced reproductive success when (i) pollinators are scarce, due to decreased visitation rates (i.e., pollinators are a limiting resource), or (ii) the shared pollinator is common, due to dilution by an increased amount of interspecific pollen transfer (Sargent, \& Ackerly, 2008). The effect on the reproductive success of competing partners is highly dependent on the density of conspecific and heterospecific individuals (Benadi and Pauw 2018) and can be modified by other factors, such as the presence of invasive super-attractive flowers (Chittka, \& Schürkens, 2001). Moreover, competition between insect and wind pollinated species for abiotic resources can also have a negative impact on insect pollinated species in terms of resource allocation to floral traits involved in pollinator attraction (Flacher et al., 2015). On the other hand, having attractive neighbours might be beneficial, as they can increase the frequency of visitations by shared pollinators (Pellissier et al., 2012), which is most effective when the coflowering species have similar floral traits or when they are super-generalists (e.g. alien species, Vilà et al., 2009). Another type of trait similarity is quite frequent among food-deceptive orchids (e.g. Traunsteinera globosa), which take advantage of and mimic the floral traits of other nectar producing neighbouring plants (in this example Trifolium pratense) - often referred to as "magnet" species - thus deceiving pollinators unable to distinguish them (Juillet, Gonzalez, Page, \& Gigord, 2007). To disentangle the two contrasting mechanisms - competition and facilitation - Mesgaran, Bouhours, Lewis, \& Cousens (2017) proposed a model for predicting the optimal density of coflowering species that is beneficial for a given plant in terms of pollination rate, and found that it is largely dependent on the attractiveness of the neighbours. Besides this modelling approach, in recent years there has been an increase in empirical studies on the density dependence of 
pollinator-mediated plant-plant interactions in natural communities (e.g. Bergamo, Streher, Traveset, Wolowski \& Sazima, 2020).

In community ecology, abiotic drivers and biotic interactions shaping species distributions are often inferred from observing functional trait patterns. Non-random trait distribution, convergent (more similar) or divergent (more dissimilar than expected by chance) trait values can indicate which mechanisms and interactions are dominant within the community. According to contemporary coexistence theory (Chesson 2000), species coexistence depends on the stabilizing effect of niche differences when fitness differences between species are small. Although this theory has been exemplified with vegetative plant functional traits (e.g. HilleRisLambers et al., 2012), one can apply the same theory to pollinator mediated plant-plant interactions as well. Coexisting plant species having similar fitness (e.g. similar display size) have similarly high probability of getting pollinated (Hegland, \& Totland, 2012). However, a high degree of trait convergence and pollinator sharing increases the probability of receiving heterospecific pollen. Therefore, plant species need to separate their pollination niches in order to coexist in a community. We propose that niche partitioning between similar species can happen via three main mechanisms: (i) partitioning in time by having asynchronous flowering phenology (Oleques, Overbeck, \& de Avia, 2017); (ii) partitioning in interaction partners by specialization on particular (groups of) pollinators (e.g. difference in spectral reflectance; McEwen, \& Vamosi, 2010; van der Kooi, Pen, Staal, Stavenga, \& Elzenga, 2016) or (iii) partitioning in morphology by different pollen placement mechanisms to avoid heterospecific pollen transfer (e.g. anther position, Fantinato et al., 2017). While the above described mechanisms were extensively studied in certain clades and specialized systems (e.g. Muchhala, \& Potts, 2007; de Jager, Dreyer, \& Ellis, 2011; Muchhala, Johnsen, \& Smith, 2014), evidence on diverse multi-clade communities remains scarce. As such 
mechanisms can result in both convergent and divergent floral trait patterns, one should be cautious when inferring community assembly rules, and attempt to distinguish traits reflecting fitness differences vs. niche differences.

Contrary to vegetative functional traits, floral trait patterns of co-existing species are mainly relevant when species overlap in their time of flowering to a certain extent. Although some evidence suggests that facilitation can also occur among non-co-flowering species via maintaining pollinator populations by providing high floral diversity (Braun, \& Lortie, 2019), these interactions are poorly studied. The interplay between co-flowering plants is widely-known and well-tested, still, results remain contradictory (Jensen, Schamp, \& Belleau, 2019). Therefore, developing new tools for assessing the overlap in flowering period among co-occurring species within communities are highly encouraged (Fantinato et al., 2016).

\subsection{Biogeographical scale}

Local communities are assembled from a larger, regional pool of species via abiotic and biotic filters. Therefore, exploring functional trait patterns on larger biogeographical scales is crucial for understanding these filtering processes and thus local community assembly mechanisms. In the case of floral traits, large-scale patterns were found to be driven by climatic gradients (e.g. Rech et al., 2016), which might cause turnover in pollinator communities (e.g. Devoto, Medan, RoigAlsina, \& Montaldo, 2009), biodiversity patterns (e.g. Ollerton, Winfree, \& Tarrant, 2011), as well as geology and/or land-use types (e.g. Kühn, Bierman, Durka, \& Klotz, 2006; Binkenstein et al., 2013). On the global scale, the majority of plant species are pollinated by insects and other animals ( $78 \%$ and $94 \%$ in temperate and tropical communities, respectively) compared to the number of wind or water-pollinated ones (Ollerton et al., 2011), and only a small proportion are capable of obligate or facultative self-pollination. Another global trend is the increasing specialization of 
pollination syndromes towards the tropics (Ollerton, Johnson, \& Hingston, 2006). However, the driver behind these two trends is still unclear (Schemske, Mittelbach, Cornell, Sobel, \& Roy, 2009), and the existence of a latitudinal gradient in specialization has recently been questioned (Moles, \& Ollerton, 2016).

It is generally accepted that pollination other than via animals is selected for when pollinators become scarce or unpredictable (e.g. on islands, Barrett, Emerson, \& Mallet, 1996). Therefore, under unsuitable conditions for pollinators, species with alternative reproductive strategies become more abundant. Based on a global community dataset, Rech et al. (2016) showed that the distribution of animal- and wind-pollinated species is non-random, but related to current climatic conditions. Animal-pollination was more dominant in the tropics (warm habitats, closed vegetation with high precipitation), whereas a higher proportion of wind-pollinated species could be found on islands compared to continents (Rech et al., 2016). On the national scale of Germany, Kühn et al. (2006) found that the proportion of wind-pollinated species was most strongly correlated with wind speed and altitude (where, under both conditions, pollinator availability is generally lower) as well as open-vegetation and moist habitats (such as bogs and fens). Dominance of self-pollination was spatially more scattered, especially in areas that included habitats with high disturbance, areas with a high proportion of alien species (e.g. riverbanks) and a high proportion of annual species. It has also been shown that oceanic islands host a surprisingly high proportion of self-compatible species (Lord, 2015; Grossenbacher et al., 2017) which therefore suggests that securing sexual reproduction when the number of potential outcrossing partners is limited is crucial for colonization success in remote locations (Baker 1955).

Considering biomes on the global scale, the ratio of outcrossing compared to selfing declines with increasing latitude and is - in some cases - significantly different among major 
biomes (Moeller et al., 2017). However, these patterns are most likely due to the distribution of life forms rather than a consequence of actual plant-pollinator interactions, as there is a strong correlation between the rate of outcrossing and life form, as expected in general (Michalski, \& Durka, 2009).

Although certain life forms have a higher proportion of certain pollination types (Michalski, \& Durka, 2009; but see Ollerton et al., 2011) and mating systems (Moeller et al, 2017), it is less known how floral traits relate to other functional traits. Within communities, the proportion of pollination types was found to be correlated to certain optical spectral signals detected by remote sensing (Feilhauer, Doktor, Schmidtlein, \& Skidmore, 2016). Based on models predicting leaf traits from spectral data, a number of strong correlations were detected between the community weighted mean (CWM) values of leaf traits and pollination types. The CWM of specific leaf area (SLA) and leaf dry mass were positively related to the proportion of insect pollination and negatively to wind pollination, whereas for leaf dry matter content (LDMC) the relationship was reversed, and none of the traits were related to selfing. However, as CWM values were used throughout this study, the correlation between vegetative and reproductive traits at the species level remains unexplored. An assessment on whether pollination-related traits form an independent axis of plant strategy is still lacking (but see Salguero-Gómez et al., 2016 for an assessment using reproduction related parameters calculated from population matrices).

During our literature survey, we have found studies predominantly covering small scales with both small extents (i.e. samples cover small geographical areas) and grain sizes (each sample or plot is small, e.g. several square meters; for more on 'extent' and 'grain size' see Wiens, 1989). In contrast to this, among studies on the biogeographical scale (large extent in general), the majority was sampled having very coarse grain, while studies with high resolution (i.e. fine grain) 
samples are limited in number, and often not evenly distributed along the studied gradient(s). Studies that investigate patterns at grid cell level (i.e. evenly distributed) or have small grain size but high extent are virtually missing (but see Kühn et al., 2006).

\section{Availability of floral traits}

Although there are a growing number of studies using pollination-related traits in community ecology, the amount of publicly available floral trait data are not increasing nearly as rapidly. As a part of TRY (Kattge et al., 2020), the largest collection of trait databases to date, predominantly categorical traits related to floral and reproductive ecology can be found sourced from BiolFlor (Kühn, Durka, \& Klotz, 2004), Ecoflora (Fitter, \& Peat, 1994) or PLANTSdata (Green, 2009). Although there is a general gap for continuous traits (but see FReD, Arnold, Faruq, Savolainen, McOwan, \& Chittka, 2010), these are often more variable within than among species.

Floral traits are known to have considerable intraspecific variability (e.g. floral tube length, Anderson, Ros, Wiese, \& Ellis, 2014, floral scent, Delle-Vedove, Schatz, \& Dufay, 2017). This variability should be kept in mind when using database data especially on a small spatial scale. For leaf traits, there is evidence that database data can be a sufficient proxy for on-site measurements of moderately plastic traits such as LDMC, but not always for highly plastic ones, such as canopy height or SLA (Cordlandwehr et al., 2013). Although this has not been studied for the majority of floral traits, flowering phenology (measured as onset of flowering in Julian days) was shown to generally have higher inter-specific than intra-specific variability (Kazakou et al., 2014), therefore can be considered a "stable" trait, even when used as a continuous variable. However, besides trait plasticity, the suitability of database data might also depend on the strength 
of the environmental gradient (Cordlandwehr et al., 2013) and the spatial scale of the study, therefore calling for even more precautions.

Large amounts of floral trait data do exist, but these are mostly scattered or difficult to access. Old monographs (e.g. Müller, 1881, Knuth, 1898, Kugler, 1970, Faegri, \& van der Pijl, 1979), regional and national floras and other sources of "grey" literature can provide an extensive base for further syntheses of the current knowledge. However, empirical results for quantitative traits, e.g. nectar properties (Baude et al. 2016), will likely need to be collected to achieve consistent data. Despite the potential of these resources, there has been no initiative so far to pull these data together in a standardised way on a common platform, like it has been achieved for other trait groups, such as clonal traits (CLO-PLA, Klimešová, \& de Bello, 2009), fine root traits (FRED, Iversen et al., 2017) or seed traits (SID, Royal Botanic Gardens Kew, 2018). Therefore, establishing standards in the measurement of floral traits as well as compiling existing and comparable data for a larger species pool and biogeographical extent (e.g. GloPL, Bennett et al. $2018 b$ ) is one of the upcoming challenges of this field.

\section{Conclusions and future research directions}

In this synthesis we reviewed predominantly recent studies using floral and pollination-related functional traits on the community scale. We summarised the most common themes and methodological approaches, and pointed to knowledge gaps that could be explored in the future. In general, we find evidence on community level floral trait patterns to be inconsistent, mainly due to the scarcity and heterogeneity (context specificity) of empirical studies, which do not allow general conclusions, neither on the directionality of trait patterns nor on their relative importance 
compared to other functional traits. We therefore provide here a concise "catalogue" of future directions in exploring floral-trait-based community ecology to improve our understanding of these patterns and processes.

First, the necessary steps to overcome current limitations due to lack of data are:

1. Establishment of floral and pollination trait standards.

2. Compilation and organization of floral and pollination trait data into a dedicated database specifically recognizing, among others, grey literature, non-English literature and recent empirical studies.

3. Making available more trait data for larger pool of species from larger biographical extents, to enable studies beyond local scales.

4. More observational vegetation data including phenological status, focusing especially on coflowering and not only co-occurrence of species.

Secondly, based on our current knowledge of ecological function and importance for plant community assembly we propose the following groups of floral traits to be considered for future compilation and sampling efforts:

1. Flower colour, including reflectance and UV patterns (expanding already existing database: FReD, Arnold, Faruq, Savolainen, McOwan, \& Chittka, 2010)

2. Display size, including flower/inflorescence size, number of flowers in inflorescence, number of flowers/inflorescences per square meter

3. Floral morphology, including nectar tube length and floral symmetry

4. Positioning of reproductive organs inside the flower in relevance to pollen placement on the pollinator's body 
5. Floral reward production, sugar content and chemical profile

6. Floral scent chemical profile

7. Flowering phenology

8. Pollination syndrome based on or supplemented by observed pollinator species

Finally, we think that the following research directions and prospects are of particular interest:

1. Phylogenetic signal for floral traits within and across communities (encompassing large species pools) thus enabling the assessment of floral trait clustering/overdispersion in

\section{Acknowledgements}

We thank Zoltán Botta-Dukát and one anonymous reviewer for their constructive comments on

4. Pollinator mediated plant-plant interactions - such as competition and facilitation - and how these are governed by abiotic conditions in natural communities.

5. Experiments on the role of floral traits in trait-based plant community assembly testing hypotheses generated in observational studies. This may necessitate experiments distributed in areas with different pollinator communities in which plant communities with various flower trait combinations are experimentally established and monitored.

the manuscript. A. E-V., L.G., and F.d.B. were supported through the Czech Science Foundation 
448 (GAČR) grant GA16-15012S and long-term research development project RVO 67985939 (The 449 Czech Academy of Sciences).

\section{Author contributions}

The study was conceived by L.G. and A.E-V. A.E-V with major contributions from L.G., took leadership in writing the manuscript and the remaining authors contributed substantially to the different versions. All co-authors have read and approved the final version of the manuscript.

\section{Data accessibility}

This synthesis article does not contain original data.

\section{References}

460

Anderson, B., Ros, P., Wiese, T. J., \& Ellis, A. G. (2014). Intraspecific divergence and convergence of floral tube length in specialized pollination interactions. Proceedings of the Royal Society B: Biological Sciences, 281. https://doi.org/10.1098/rspb.2014.1420

Arnold, S. E., Faruq, S., Savolainen, V., McOwan, P. W., \& Chittka, L. (2010). FReD: the floral reflectance database - a web portal for analyses of flower colour. PloS ONE, 5, e14287. https://doi.org/10.1371/journal.pone.0014287

Ashman, T. L., \& Arceo-Gómez, G. (2013). Toward a predictive understanding of the fitness costs of heterospecific pollen receipt and its importance in co-flowering communities. American 
Journal of Botany, 100, 1061-1070. https://doi.org/10.3732/ajb.1200496

Baker, H. G. (1955). Self-compatibility and establishment after long distance dispersal. Evolution, 9, 347-349. https://doi.org/10.1111/j.1558-5646.1955.tb01544.x

Barrett, S. C., Emerson, B., \& Mallet, J. (1996). The reproductive biology and genetics of island plants. Philosophical Transactions: Biological Sciences 725-733.

\section{https://doi.org/10.1098/rstb.1996.0067}

Bastazini, V. A., Ferreira, P. M., Azambuja, B. O., Casas, G., Debastiani, V. J., Guimarães, P. R., \& Pillar, V. D. (2017). Untangling the tangled bank: a novel method for partitioning the effects of phylogenies and traits on ecological networks. Evolutionary Biology, 44, 312-324.

\section{https://doi.org/10.1007/s11692-017-9409-8}

Baude, M., Kunin, W. E., Boatman, N. D., Conyers, S., Davies, N., Gillespie, M. A. K., ..., \& Memmott, R. D. (2016). Historical nectar assessment reveals the fall and rise of floral resources in Britain. Nature, 530, 85-88. https://doi.org/10.1038/nature16532

Benadi, G., \& Pauw, A. (2018). Frequency dependence of pollinator visitation rates suggests that pollination niches can allow plant species coexistence. Journal of Ecology, 106, 1892-1901.

\section{https://doi.org/10.1111/1365-2745.13025}

Bennett, J. M., Thompson, A., Goia, I., Feldmann, R., Ştefan, V., Bogdan, A., ..., \& Knight, T. M. (2018a). A review of European studies on pollination networks and pollen limitation, and a case study designed to fill in a gap. AoB Plants, 10, ply068.

\section{https://doi.org/10.1093/aobpla/ply068}

Bennett, J. M., Steets, J. A., Burns, J. H., Durka, W., Vamosi, J. C., Arceo-Gómez, G., ..., \& Knight, T. M. (2018b). GloPL, a global data base on pollen limitation of plant reproduction. 
490

491

492

493

494

495

496

497

498

499

500

501

502

503

504

505

506

507

508

509

510

511

Scientific Data, 5, 180249. https://doi.org/10.1038/sdata.2018.249

Bergamo, P. J., Streher, N. S., Traveset, A., Wolowski, M., \& Sazima, M. (2020). Pollination outcomes reveal negative density-dependence coupled with interspecific facilitation among plants. Ecology letters, 23, 129-139. https://doi.org/10.1111/ele.13415

Binkenstein, J., Renoult, J. P., \& Schaefer, H. M. (2013). Increasing land-use intensity decreases floral colour diversity of plant communities in temperate grasslands. Oecologia, 173, 461-471. https://doi.org/10.1007/s00442-013-2627-6

Blüthgen, N., Menzel, F., Hovestadt, T., Fiala, B., \& Blüthgen, N. (2007). Specialization, constraints, and conflicting interests in mutualistic networks. Current biology, 17, 341-346. https://doi.org/10.1016/j.cub.2006.12.039

Bosch, J., Retana, J., \& Cerda, X. (1997). Flowering phenology, floral traits and pollinator composition in a herbaceous Mediterranean plant community. Oecologia, 109, 583-591.

\section{https://doi.org/10.1007/s004420050120}

Braun, J., \& Lortie, C. (2019). Finding the bees knees: a conceptual framework and systematic review of the mechanisms of pollinator-mediated facilitation. Perspectives in Plant Ecology, Evolution and Systematics, 36, 33-40. https://doi.org/10.1016/j.ppees.2018.12.003

Burkle, L. A., \& Irwin, R. E. (2010). Beyond biomass: Measuring the effects of community-level nitrogen enrichment on floral traits, pollinator visitation and plant reproduction. Journal of Ecology, 98, 705-717. https://doi.org/10.1111/j.1365-2745.2010.01648.x

Chamberlain, S. A., Cartar, R. V., Worley, A. C., Semmler, S. J., Gielens, G., Elwell, S., ..., \& Elle, E. (2014). Traits and phylogenetic history contribute to network structure across Canadian plant-pollinator communities. Oecologia, 176, 545-556. https://doi.org/10.1007/s00442-014- 
513

514

515

516

517

518

519

520

521

522

523

524

525

526

527

528

529

530

531

532

533

Chesson, P. (2000). Mechanisms of maintenance of species diversity. Annual review of Ecology and Systematics, 31, 343-366. https://doi.org/10.1146/annurev.ecolsys.31.1.343

Chittka, L., \& Schürkens, S. (2001). Successful invasion of a floral market - An exotic Asian plant has moved in on Europe's river-banks by bribing pollinators. Nature, 411, 653-653.

\section{https://doi.org/10.1038/35079676}

Cordlandwehr, V., Meredith, R. L., Ozinga, W. A., Bekker, R. M., Groenendael, J. M., Bakker, J. P. (2013). Do plant traits retrieved from a database accurately predict on-site measurements? Journal of Ecology, 101, 662-670. https://doi.org/10.1111/1365-2745.12091

Cornwell, W. K., \& Ackerly, D. D. (2009). Community assembly and shifts in plant trait distributions across an environmental gradient in coastal California. Ecological Monographs, 79, 109-126. https://doi.org/10.1890/07-1134.1

Craine, J.M., Wolkovich, E.M., Towne, E.G. \& Kembel, S.W. (2012) Flowering phenology as a functional trait in a tallgrass prairie. New Phytologist, 193, 673-682.

https://doi.org/10.1111/j.1469-8137.2011.03953.x

Delle-Vedove, R., Schatz, B., \& Dufay, M. (2017). Understanding intraspecific variation of floral scent in light of evolutionary ecology. Annals of Botany, 120, 1-20.

https://doi.org/10.1093/aob/mcx055

de Deus, F. F., \& Oliveira, P. E. (2016). Changes in floristic composition and pollination systems in a "Cerrado" community after 20 years of fire suppression. Revista Brasileira de Botanica, 39, 1051-1063. https://doi.org/10.1007/s40415-016-0304-9

Devoto, M., Medan, D., ROIG-ALSINA, A., \& Montaldo, N. H. (2009). Patterns of species 
turnover in plant-pollinator communities along a precipitation gradient in Patagonia (Argentina). Austral Ecology, 34, 848-857. https://doi.org/10.1111/j.1442-9993.2009.01987.x

Díaz, S., Cabido, M., \& Casanoves, F. (1998). Plant functional traits and environmental filters at a regional scale. Journal of Vegetation Science, 9, 113-122. https://doi.org/10.2307/3237229

Fabbro, T., \& Körner, C. (2004). Altitudinal differences in flower traits and reproductive allocation. Flora - Morphology, Distribution, Functional Ecology of Plants, 199, 70-81. https://doi.org/10.1078/0367-2530-00128

Faegri, K., \& van der Pijl, L. (1979). Principles of pollination ecology. Oxford, UK: Pergamon Press.

Fantinato, E., Del Vecchio, S., Slaviero, A., Conti, L., Acosta, A. T. R., \& Buffa, G. (2016).

Does flowering synchrony contribute to the sustainment of dry grassland biodiversity? Flora: Morphology, Distribution, Functional Ecology of Plants, 222, 96-103.

\section{https://doi.org/10.1016/j.flora.2016.04.003}

Fantinato, E., Del Vecchio, S., Giovanetti, M., Acosta, A. T. R., \& Buffa, G. (2017). New insights into plants coexistence in species-rich communities: the pollination interaction perspective. Journal of Vegetation Science, 29, 6-14. https://doi.org/10.1111/jvs.12592

Feilhauer, H., Doktor, D., Schmidtlein, S., \& Skidmore, A. K. (2016). Mapping pollination types with remote sensing. Journal of Vegetation Science, 27, 999-1011.

\section{https://doi.org/10.1111/jvs.12421}

Feldman, T. S., Morris, W. F., \& Wilson, W. G. (2004). When can two plant species facilitate each other's pollination? Oikos, 105, 197-207. https://doi.org/10.1111/j.0030$\underline{1299.2004 .12845 . x}$ 
Fitter, A. H., \& Peat, H. J. (1994). The ecological flora database. - Journal of Ecology, 82, 415425. https://doi.org/10.2307/2261309

Flacher, F., Raynaud, X., Hansart, A., Motard, E., \& Dajoz, I. (2015). Competition with windpollinated plant species alters floral traits of insect-pollinated plant species. Scientific Reports 5. https://doi.org/10.1038/srep13345

Fornoff, F., Klein, A. M., Hartig, F., Benadi, G., Venjakob, C., Schaefer, H. M., \& Ebeling, A. (2017). Functional flower traits and their diversity drive pollinator visitation. Oikos, 126, 10201030. https://doi.org/10.1111/oik.03869

Götzenberger, L., de Bello, F., Bråthen, K. A., Davison, J., Dubuis, A., Guisan, A., ... \& Zobel, M. (2012). Ecological assembly rules in plant communities - approaches, patterns and prospects. Biological Reviews, 87, 111-127. https://doi.org/10.1111/j.1469-185X.2011.00187.x

Green, W. (2009). USDA PLANTS Compilation, version 1, 09-02-02. (http://plants.usda.gov, 14 March 2018).

Grossenbacher, D. L., Brandvain, Y., Auld, J. R., Burd, M., Cheptou, P.-O., Conner, J. K., ..., \& Goldberg, E. E. (2017). Self-compatibility is over-represented on islands. New Phytologist, 215, 469-478. https://doi.org/10.1111/nph.14534

Hegland, S. J., \& Totland, Ø. (2012). Interactions for pollinator visitation and their consequences for reproduction in a plant community. Acta Oecologica, 43, 95-103.

$\underline{\text { https://doi.org/10.1016/j.actao.2012.06.002 }}$

HilleRisLambers, J., Adler, P. B., Harpole, W. S., Levine, J. M., \& Mayfield, M. M. (2012).

Rethinking community assembly through the lens of coexistence theory. Annual review of ecology, evolution, and systematics, 43, 227-248. https://doi.org/10.1146/annurev-ecolsys- 


\section{1-160411}

Ibanez, S. (2012). Optimizing size thresholds in a plant-pollinator interaction web: towards a mechanistic understanding of ecological networks. Oecologia, 170, 233-242. https://doi.org/10.1007/s00442-012-2290-3

Ibanez, S., Lavorel, S., Puijalon, S., \& Moretti, M. (2013). Herbivory mediated by coupling between biomechanical traits of plants and grasshoppers. Functional Ecology, 27, 479-489. https://doi.org/10.1111/1365-2435.12058

Iversen, C. M., McCormack, M. L., Powell, A. S., Blackwood, C. B., Freschet, G. T., Kattge, J., ..., \& Bodegom, P. M. (2017). A global Fine-Root Ecology Database to address below-ground challenges in plant ecology. New Phytologist, 215, 15-26. https://doi.org/10.1111/nph.14486

de Jager, M. L., Dreyer, L. L., \& Ellis, A. G. (2011). Do pollinators influence the assembly of flower colours within plant communities?. Oecologia, 166, 543-553.

\section{https://doi.org/10.1007/s00442-010-1879-7}

Jensen, A. M., Schamp, B. S., \& Belleau, A. (2019). Evidence of temporal niche separation over low flowering time overlap in an old-field plant community. Oecologia, 1-12.

\section{https://doi.org/10.1007/s00442-019-04386-0}

Juillet, N., Gonzalez, M. A., Page, P. A., \& Gigord, L. D. B. (2007). Pollination of the European food-deceptive Traunsteinera globosa (Orchidaceae): The importance of nectar-producing neighbouring plants. Plant Systematics and Evolution, 265, 123-129.

\section{https://doi.org/10.1007/s00606-006-0507-9}

Junker, R. R., Blüthgen, N., Brehm, T., Binkenstein, J., Paulus, J., Martin Schaefer, H., \& Stang, M. (2013). Specialization on traits as basis for the niche-breadth of flower visitors and as 
600

601

602

603

604

605

606

607

608

609

610

611

612

613

614

615

616

617

618

619

620

621

structuring mechanism of ecological networks. Functional Ecology, 27, 329-341.

https://doi.org/10.1111/1365-2435.12005

Junker, R. R., Blüthgen, N., \& Keller, A. (2015). Functional and phylogenetic diversity of plant communities differently affect the structure of flower-visitor interactions and reveal convergences in floral traits. Evolutionary Ecology, 29, 437-450.

https://doi.org/10.1007/s10682-014-9747-2

Junker, R. R., \& Larue-Kontic, A. A. C. (2018). Elevation predicts the functional composition of alpine plant communities based on vegetative traits, but not based on floral traits. Alpine Botany, 128, 13-22. https://doi.org/10.1007/s00035-017-0198-6

Kantsa, A., Raguso, RA, Dyer, AG, Sgardelis, SP, Olesen, JM, \& Petanidou, T. (2017).

Community-wide integration of floral colour and scent in a Mediterranean scrubland. Nature ecology \& evolution, 1, 1502-1510. https://doi.org/10.1038/s41559-017-0298-0

Kantsa, A., Raguso, RA, Dyer, AG, Olesen, JM, Tscheulin, T., \& Petanidou, T. (2018).

Disentangling the role of floral sensory stimuli in pollination networks. Nature communications, 9, 1041. https://doi.org/10.1038/s41467-018-03448-w

Karron, J. D., Ivey, C. T., Mitchell, R. J., Whitehead, M. R., Peakall, R., Case, A. L. (2012).

New perspectives on the evolution of plant mating systems. Annals of Botany, 109, 493-503.

https://doi.org/10.1093/aob/mcr319

Kattge, J., Bönisch, G, Díaz, S., Lavorel, S., Prentice, I. C., Leadley, P., ..., \& Wirth, C. (2020).

TRY plant trait database - enhanced coverage and open access. Global Change Biology, 26, 119 188. https://doi.org/10.1111/gcb.14904

Kazakou, E., Violle, C., Roumet, C., Navas, M. L., Vile, D., Kattge, J., \& Garnier, E. (2014). 
622

623

624

625

626

627

628

629

630

631

632

633

634

635

636

637

638

639

640

641

642

643

Are trait-based species rankings consistent across data sets and spatial scales?. Journal of Vegetation Science, 25, 235-247. https://doi.org/10.1111/jvs.12066

Kemp, J. E., Bergh, N. G., Soares, M., \& Ellis, A. G. (2019). Dominant pollinators drive nonrandom community assembly and shared flower colour patterns in daisy communities. Annals of botany, 123, 277-288. https://doi.org/10.1093/aob/mcy126

Klimešová, J., \& de Bello, F. (2009). CLO-PLA: the database of clonal 817 and bud bank traits of Central European flora. Journal of Vegetation Science, 20, 511-516.

https://doi.org/10.1111/i.1654-1103.2009.01050.x

Klimešová, J., Danihelka, J., Chrtek, J., de Bello, F., \& Herben, T. (2017). CLO-PLA: A database of clonal and bud-bank traits of the Central European flora. Ecology, 98, 1179-1179.

https://doi.org/10.1002/ecy.1745

Klotz, S., Kühn, I., \& Durka,W. (2002). BIOLFLOR - Eine Datenbank zu biologischökologischen Merkmalen der Flora von Deutschland. Bundesamt für Naturschutz, Bonn.

Knight, T. M., Ashman, T. L., Bennett, J. M., Burns, J. H., Passonneau, S., \& Steets, J. A. (2018). Reflections on, and visions for, the changing field of pollination ecology. Ecology letters, 21, 1282-1295. https://doi.org/10.1111/ele.13094

Knuth, P. (1898). Handbuch der Blüthenbiologie. Leipzig: W. Engelmann.

van der Kooi, C. J., Pen, I., Staal, M., Stavenga, D. G., \& Elzenga, J. T. M. (2016). Competition for pollinators and intra-communal spectral dissimilarity of flowers. Plant Biology, 18, 56-62.

https://doi.org/10.1111/plb.12328

Kugler, H. (1970). Blütenökologie. 2nd edition. Jena: G. Fischer.

Kühn, I., Durka, W., \& Klotz, S. (2004). BiolFlor: a new plant-trait database as a tool for plant 
644

645

646

647

648

649

650

651

652

653

654

655

656

657

658

659

660

661

662

663

664

665

invasion ecology. Diversity and Distributions, 10, 363-365.

Kühn, I., Bierman, S. M., Durka, W., \& Klotz, S. (2006). Relating geographical variation in pollination types to environmental and spatial factors using novel statistical methods. New Phytologist, 172, 127-139. https://doi.org/10.1111/j.1469-8137.2006.01811.x

Laigle, I., Aubin, I., Digel, C., Brose, U., Boulangeat, I., \& Gravel, D. (2018). Species traits as drivers of food web structure. Oikos, 127, 316-326. https://doi.org/10.1111/oik.04712

Larson, J. E., \& Funk, J. L. (2016). Regeneration: an overlooked aspect of trait-based plant community assembly models. Journal of Ecology, 104, 1284-1298.

https://doi.org/10.1111/1365-2745.12613

Lavorel, S., Garnier, E. (2002). Predicting changes in community composition and ecosystem functioning from plant traits: revisiting the Holy Grail. Functional Ecology, 16, 545-556. https://doi.org/10.1046/j.1365-2435.2002.00664.x

Lavorel, S., Storkey, J., Bardgett, R. D., de Bello, F., Berg, M. P., Le Roux, X., ... \& Harrington, R. (2013). A novel framework for linking functional diversity of plants with other trophic levels for the quantification of ecosystem services. Journal of Vegetation Science, 24, 942-948.

https://doi.org/10.1111/jvs.12083

Lázaro, A., Hegland, S. J., \& Totland, Ø. (2008). The relationships between floral traits and specificity of pollination systems in three Scandinavian plant communities. Oecologia, 157, 249257. https://doi.org/10.1007/s00442-008-1066-2

Lázaro, A., Lundgren, R., \& Totland, Ø. (2015). Pollen limitation, species’ floral traits and pollinator visitation: Different relationships in contrasting communities. Oikos, 124, 174-186. https://doi.org/10.1111/oik.01525 
666

667

668

669

670

671

672

673

674

675

676

677

678

679

680

681

682

683

684

685

686

687

Lord, J. M. (2015). Patterns in floral traits and plant breeding systems on Southern Ocean Islands. AoB Plants, 7, plv095. https://doi.org/10.1093/aobpla/plv095

Losos, J. B. (2008). Phylogenetic niche conservatism, phylogenetic signal and the relationship between phylogenetic relatedness and ecological similarity among species. Ecology letters, 11, 995-1003. https://doi.org/10.1111/j.1461-0248.2008.01229.x

Maglianesi, M. A., Blüthgen, N., Böhning-Gaese, K., \& Schleuning, M. (2014). Morphological traits determine specialization and resource use in plant-hummingbird networks in the neotropics. Ecology, 95, 3325-3334. https://doi.org/10.1890/13-2261.1

Makrodimos, N., Blionis, G. J., Krigas, N., \& Vokou, D. (2008). Flower morphology, phenology and visitor patterns in an alpine community on Mt Olympos, Greece. Flora: Morphology, Distribution, Functional Ecology of Plants, 203, 449-468.

\section{https://doi.org/10.1016/j.flora.2007.07.003}

McEwen, J. R., \& Vamosi, J. C. (2010). Floral colour versus phylogeny in structuring subalpine flowering communities. Proceedings of the Royal Society B: Biological Sciences, 277, 29572965. https://doi.org/10.1098/rspb.2010.0501

Mesgaran, M. B., Bouhours, J., Lewis, M. A., \& Cousens, R. D. (2017). How to be a good neighbour: Facilitation and competition between two co-flowering species. Journal of Theoretical Biology, 422, 72-83. https://doi.org/10.1016/j.jtbi.2017.04.011

Michalski, S. G., \& Durka, W. (2009). Pollination mode and life form strongly affect the relation between mating system and pollen to ovule ratios. New Phytologist, 183, 470-479.

https://doi.org/10.1111/j.1469-8137.2009.02861.x

Mitchell, R. J., Flanagan, R. J., Brown, B. J., Waser, N. M., \& Karron, J. D. (2009). New 
688

689

690

691

692

693

694

695

696

697

698

699

700

701

702

703

704

705

706

707

708

709

frontiers in competition for pollination. Annals of Botany, 103, 1403-1413.

https://doi.org/10.1093/aob/mcp062

Moeller, D. A., Runquist, R. D. B., Moe, A. M., Geber, M. A., Goodwillie, C., Cheptou, P.-O., .., \& Winn, A. A. (2017). Global biogeography of mating system variation in seed plants.

Ecology Letters, 20, 375-384. https://doi.org/10.1111/ele.12738

Moles, A. T., \& Ollerton, J. (2016). Is the notion that species interactions are stronger and more specialized in the tropics a zombie idea? Biotropica, 48, 141-145.

https://doi.org/10.1111/btp.12281

Muchhala, N., \& Potts, M. D. (2007). Character displacement among bat-pollinated flowers of the genus Burmeistera: analysis of mechanism, process and pattern. Proceedings of the Royal Society B: Biological Sciences, 274, 2731-2737. https://doi.org/10.1098/rspb.2007.0670

Muchhala, N., Johnsen, S., \& Smith, S. D. (2014). Competition for hummingbird pollination shapes flower color variation in Andean Solanaceae. Evolution, 68, 2275-2286.

\section{https://doi.org/10.1111/evo.12441}

Müller, H. (1881). Alpenblumen, ihre Befruchtung durch Insekten und ihre Anpassungen an dieselben. Leipzig: W. Engelmann.

Oleques, S. S., Overbeck, G. E., \& de Avia, R. S. (2017). Flowering phenology and plantpollinator interactions in a grassland community of Southern Brazil. Flora: Morphology, Distribution, Functional Ecology of Plants, 229, 141-146.

https://doi.org/10.1016/j.flora.2017.02.024

Ollerton, J., Johnson, S. D., \& Hingston, A. B. (2006). Geographical Variation in Diversity and Specificity of Pollination Systems. In N. M. Waser \& J. Ollerton (Eds.), Plant-pollinator 
interactions: from specialization to generalization (pp. 283-308). Chicago, US: The University of Chicago Press.

Ollerton, J., Alarcón, R., Waser, N. M., Price, M. V., Watts, S., Cranmer, L., Hingston, A., Peter, C. I. \& Rotenberry, J. (2009). A global test of the pollination syndrome hypothesis. Annals of botany, 103, 1471-1480. https://doi.org/10.1093/aob/mcp031

Ollerton, J., Winfree, R., \& Tarrant, S. (2011). How many flowering plants are pollinated by animals? Oikos, 120, 321-326. https://doi.org/10.1111/j.1600-0706.2010.18644.x

Pauw, A. (2013). Can pollination niches facilitate plant coexistence? Trends in ecology \& evolution, 28, 30-37. https://doi.org/10.1016/j.tree.2012.07.019

Pauw, A. (2018). Flower wars. Journal of Vegetation Science, 29, 4-5.

https://doi.org/10.1111/jvs.12603

Pellissier, L., Pottier, J., Vittoz, P., Dubuis, A., \& Guisan, A. (2010). Spatial pattern of floral morphology: Possible insight into the effects of pollinators on plant distributions. Oikos, 119, 1805-1813. https://doi.org/10.1111/j.1600-0706.2010.18560.x

Pellissier, L., Alvarez, N., \& Guisan, A. (2012). Pollinators as drivers of plant distribution and assemblage into communities. In S. Patiny (Ed.), Evolution of Plant-Pollinator Relationships (pp. 392-413). Cambridge, UK: Cambridge University Press.

Pellissier, L., Albouy, C., Bascompte, J., Farwig, N., Graham, C., Loreau, M., Maglianesi, M. A., Melián, C. J, Pitteloud, C., Roslin, T., Rohr, R., Saavedra, S., Thuiller, W., Woodward, G., Zimmermann, N. E. \& Gravel, D. (2018). Comparing species interaction networks along environmental gradients. Biological Reviews, 93, 785-800. https://doi.org/10.1111/brv.12366

Pennell, M. W., FitzJohn, R. G., Cornwell, W. K., \& Harmon, L. J. (2015). Model adequacy and 
the macroevolution of angiosperm functional traits. The American Naturalist, 186, E33-E50.

\section{https://doi.org/10.1086/682022}

Pérez-Harguindeguy, N., Diaz, S., Gamier, E., Lavorel, S., Poorter, H., Jaureguiberry, P., ... \& Urcelay, C. (2013). New handbook for standardised measurement of plant functional traits worldwide. Australian Journal of Botany, 61, 167-234. https://doi.org/10.1071/BT12225_CO

Rafferty, N. E., \& Ives, A. R. (2013). Phylogenetic trait-based analyses of ecological networks. Ecology, 94, 2321-2333. https://doi.org/10.1890/12-1948.1

Rech, A. R., Dalsgaard, B., Sandel, B., Sonne, J., Svenning, J.-C., Holmes, N., \& Ollerton, J. (2016). The macroecology of animal versus wind pollination: ecological factors are more important than historical climate stability. Plant Ecology and Diversity, 9, 253-262.

\section{https://doi.org/10.1080/17550874.2016.1207722}

Reverté, S., Retana, J., Gómez, J. M., \& Bosch, J. (2016). Pollinators show flower colour preferences but flowers with similar colours do not attract similar pollinators. Annals of Botany, 118, 249-257. https://doi.org/10.1093/aob/mcw103

Rosas-Guerrero, V., Aguilar, R., Martén-Rodríguez, S., Ashworth, L., Lopezaraiza-Mikel, M., Bastida, J. M., \& Quesada, M. (2014). A quantitative review of pollination syndromes: do floral traits predict effective pollinators? Ecology letters, 17, 388-400.

https://doi.org/10.1111/ele.12224

Royal Botanic Gardens Kew. (2018). Seed Information Database (SID). Version 7.1. Available from: http://data.kew.org/sid/

Salguero-Gómez, R., Jones, O. R., Jongejans, E., Blomberg, S. P., Hodgson, D. J., Mbeau-Ache, C., Zuidema, P. A., de Kroon, H., \& Buckley, Y. M. (2016). Fast-slow continuum and 
754

755

756

757

758

759

760

761

762

763

764

765

766

767

768

769

770

771

772

773

774

775

reproductive strategies structure plant life-history variation worldwide. Proceedings of the National Academy of Sciences, 113, 230-235. https://doi.org/10.1073/pnas.1506215112

Sargent, R. D., \& Ackerly, D. D. (2008). Plant-pollinator interactions and the assembly of plant communities. Trends in Ecology and Evolution, 23, 123-130.

https://doi.org/10.1016/j.tree.2007.11.003

Sazatornil, F. D., Moré, M., Benitez-Vieyra, S., Cocucci, A. A., Kitching, I. J., Schlumpberger, B. O., ... \& Amorim, F. W. (2016). Beyond neutral and forbidden links: morphological matches and the assembly of mutualistic hawkmoth-plant networks. Journal of Animal Ecology, 85, 1586-1594. https://doi.org/10.1111/1365-2656.12509

Schemske, D. W., Mittelbach, G. G., Cornell, H. V., Sobel, J. M., \& Roy, K. (2009). Is There a Latitudinal Gradient in the Importance of Biotic Interactions? Annual Review of Ecology, Evolution, and Systematics, 40, 245-269.

https://doi.org/10.1146/annurev.ecolsys.39.110707.173430

Schleuning, M., Fründ, J., \& García, D. (2015). Predicting ecosystem functions from biodiversity and mutualistic networks: an extension of trait-based concepts to plant-animal interactions. Ecography, 38, 380-392. https://doi.org/10.1111/ecog.00983

Shrestha, M., Dyer, A. G., Bhattarai, P., \& Burd, M. (2014). Flower colour and phylogeny along an altitudinal gradient in the Himalayas of Nepal. Journal of Ecology, 102, 126-135.

https://doi.org/10.1111/1365-2745.12185

Souza, CS, Maruyama, PK, Aoki, C, Sigrist, MR, Raizer, J, Gross, CL, Araujo, AC (2018)

Temporal variation in plant-pollinator networks from seasonal tropical environments: Higher specialization when resources are scarce. Journal of Ecology, 106, 2409-2420. 
Tinoco, B. A., Graham, C. H., Aguilar, J. M., \& Schleuning, M. (2017). Effects of hummingbird morphology on specialization in pollination networks vary with resource availability. Oikos, 126, 52-60. https://doi.org/10.1111/oik.02998

Vamosi, J. C., Moray, C. M., Garcha, N. K., Chamberlain, S. A., \& Mooers, A. (2014).

Pollinators visit related plant species across 29 plant-pollinator networks. Ecology and Evolution, 4, 2303-2315. https://doi.org/10.1002/ece3.1051

Vázquez, D. P., Blüthgen, N., Cagnolo, L., \& Chacoff, N. P. (2009). Uniting pattern and process in plant-animal mutualistic networks: a review. Annals of Botany, 103, 1445-1457.

https://doi.org/10.1093/aob/mcp057

Vilà, M., Bartomeus, I., Dietzsch, A. C., Petanidou, T., Steffan-Dewenter, I., Stout, J. C., \& Tscheulin, T. (2009). Invasive plant integration into native plant-pollinator networks across Europe. Proceedings of the Royal Society of London B: Biological Sciences, 276, 3887-3893. https://doi.org/10.1098/rspb.2009.1076

Violle, C., Navas, M. L., Vile, D., Kazakou, E., Fortunel, C., Hummel, I., \& Garnier, E. (2007).

Let the concept of trait be functional! Oikos, 116, 882-892. https://doi.org/10.1111/j.0030$\underline{1299.2007 .15559 . x}$

Warring, B., Cardoso, F. C. G., Marques, M. C. M., \& Varassin. I. G. (2016). Functional diversity of reproductive traits increases across succession in the Atlantic forest. Rodriguesia, 67, 321-333. https://doi.org/10.1590/2175-7860201667204

Westoby, M. (1998). A leaf-height-seed (LHS) plant ecology strategy scheme. Plant and Soil, 199, 213-227. https://doi.org/10.1023/A:1004327224729 
798 Wiens, J. A. (1989). Spatial scaling in ecology. Functional ecology, 3, 385-397.

799 https://doi.org/10.2307/2389612

800 Wolowski, M., Carvalheiro, L. G., \& Freitas, L. (2017). Influence of plant-pollinator interactions

801 on the assembly of plant and hummingbird communities. Journal of Ecology, 105, 332-344.

802 https://doi.org/10.1111/1365-2745.12684

803 Zobel, M. (2016). The species pool concept as a framework for studying patterns of plant

804 diversity. Journal of Vegetation Science, 27, 8-18. https://doi.org/10.1111/jvs.12333

805

806

807 Supplementary Information

808 Appendix S1. Short summary of studies resulted from the systematic literature search in Web of 809 Science.

810 


\begin{tabular}{|c|c|c|c|c|}
\hline & Type of approach & Metrics & R packages & Examples \\
\hline $\mathbf{A}$ & Visitation networks & $\begin{array}{l}\text { Network structure and } \\
\text { motifs: nestedness, } \\
\text { connectivity, } \\
\text { modularity }\end{array}$ & $\begin{array}{l}\text { bipartite, } \\
\text { bmotif }\end{array}$ & Bennett et al. 2018a \\
\hline B & $\begin{array}{l}\text { Phylogenetic signal, } \\
\text { evolution of traits }\end{array}$ & $\begin{array}{l}\text { Indices of } \\
\text { phylogenetic signal: } \\
\text { Pagel's } \lambda \text {, } \\
\text { Blomberg's K }\end{array}$ & $\begin{array}{l}\text { ape, phytools, } \\
\text { phangorn, } \\
\text { picante }\end{array}$ & $\begin{array}{l}\text { Chamberlain et al. } \\
2014 \text {, Reverté et al. } \\
2016\end{array}$ \\
\hline C & $\begin{array}{l}\text { Community } \\
\text { composition and } \\
\text { diversity }\end{array}$ & $\begin{array}{l}\text { Classical diversity } \\
\text { indices: Shannon, } \\
\text { Simpson }\end{array}$ & vegan & $\begin{array}{l}\text { Bosch et al. } 1997 \\
\text { de Deus and } \\
\text { Oliviera } 2016\end{array}$ \\
\hline $\mathbf{A B}$ & $\begin{array}{l}\text { Trait matching, testing } \\
\text { of pollination } \\
\text { syndromes }\end{array}$ & $\begin{array}{l}\text { Network structure } \\
\text { functional and } \\
\text { phylogenetic } \\
\text { dissimilarities }\end{array}$ & $\begin{array}{l}\text { bipartite, } \\
\text { vegan, FD, } \\
\text { picante }\end{array}$ & $\begin{array}{l}\text { Chamberlain et al. } \\
2014\end{array}$ \\
\hline $\mathrm{AC}$ & $\begin{array}{l}\text { Network stability, } \\
\text { ecosystem services }\end{array}$ & $\begin{array}{l}\text { Network properties } \\
\text { related to diversity } \\
\text { measures }\end{array}$ & bipartite & Souza et al. 2018 \\
\hline BC & $\begin{array}{l}\text { Species coexistence } \\
\text { related to functional } \\
\text { traits and phylogeny }\end{array}$ & $\begin{array}{l}\text { Functional diversity } \\
\text { indices, phylogenetic } \\
\text { clustering / } \\
\text { overdispersion }\end{array}$ & $\begin{array}{l}\text { vegan, } \\
\text { picante, FD, } \\
\text { ape }\end{array}$ & Fornoff et al. 2017 \\
\hline $\mathbf{A B C}$ & $\begin{array}{l}\text { Visitor specialization } \\
\text { and pollination niche } \\
\text { breadth based on } \\
\text { floral traits }\end{array}$ & $\begin{array}{l}\text { Network properties } \\
\text { related to trait } \\
\text { diversity and } \\
\text { phylogeny }\end{array}$ & $\begin{array}{l}\text { under } \\
\text { development }\end{array}$ & $\begin{array}{l}\text { Junker et al. } 2013 \text {, } \\
\text { Kemp et al. } 2019\end{array}$ \\
\hline
\end{tabular}

Table 1. Types of methodological approaches used for answering research questions on the importance of floral traits in the structuring of plant (and pollinator) communities, metrics, methodological tools within the R statistical environment (R Development Core Team 2019) and examples from the literature. The lettering of approaches (A, B, C...) follows Figure 1.

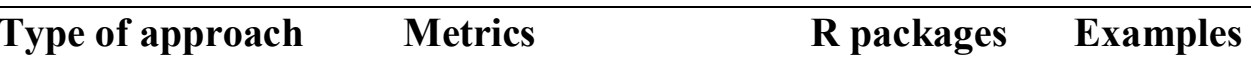




\section{COMMUNITY SCALE STUDIES}

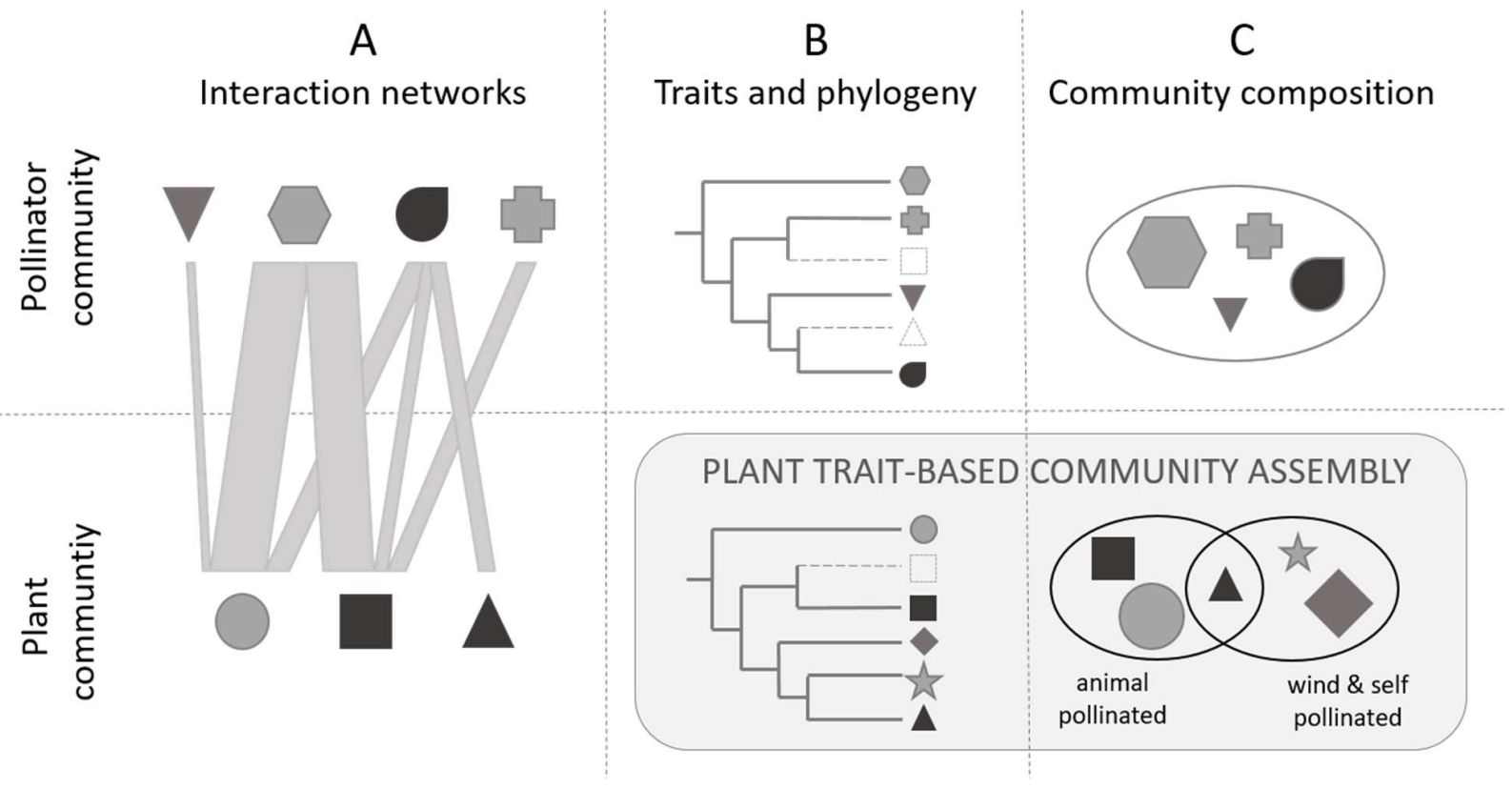

817 Figure 1. The most common approaches to study plant and pollinator communities. A,

818 pollination networks; B, phylogenetic signal of floral traits; C, species co-occurrence studies

819 (abundance or frequency-based); and the combination of these: $\mathrm{AB}$, trait-matching in plants and

820 pollinators and the testing of pollination syndromes; AC, pollination networks in plant

821 communities taking into account the abundance and co-occurrence of species; BC, species co-

822 existence patterns driven by floral traits and/or phylogenetic relationships (i.e. highlighted area,

823 indicating the main focus of this synthesis). $\mathrm{ABC}$, functional trait-based community assembly

824 driven by trophic interactions. The different shades and shapes represent different functional trait

825 values. The sizes of shapes are proportional to species abundances. In section B empty symbols

826 with dashed branches represent species present in the habitat species pool but missing from local

827 communities. Thus, approaches of section B generally work on the habitat species pool rather

828 than on the plot level. 